\title{
The Study of the Model of Community Service for Home Care of the Elderly at New Period
}

\author{
Kang Hongge $^{1 *}$, Zhang Guowang ${ }^{2}$ \\ Tianjin University of Commerce, Tianjin 300134, China \\ 1065867994@qq.com, zhanggw2000@yahoo.com.cn
}

\begin{abstract}
Based on classifying the significance of the model of supporting the aged, the models of family care and institution care of the elderly are compared; meanwhile, the innovative forms and the creative model are proposed. Reference value for improving social model of caring the elderly is provided.
\end{abstract}

Index Terms - New period, Model of caring the aged, community service

\section{Introduction}

As the society and economy develop, the quantity of the aged people continues to increase, and the society begins to focus on the service for caring the elderly. According to statistical standard of the United Nations, in one country, if the people who are sixty years of age and older accounts for $10 \%$ of the total population, or the people who are sixty-five years of age and older more than 7\%, the country is an aged tendency population country. China has become an aged tendency of population country since 1999. According to the data of the sixth nationwide population census, the number of people over sixty years old is 17,765 , taking 13.26 percentages of total number. Among these people, the number of those over sixty-five is 11,883 , taking 8.9 percentages of total number. The elderly take up a larger and larger percentage. It's estimated that the number of aged people will reach 248 million, constituting $17.17 \%$ of total Chinese population in 2020. And in 2050, the number will become 400 million, constituting over $30 \%$ of total Chinese population.

As the situation of aged tendency of population aggravates, the problem of caring the elderly has become a prominent problem that cannot be neglected. In order to solve the problem coming with the aged tendency of population preferably, family and housing institution care of the elderly will be discussed in this paper, referring to many models of caring the aged people at domestic and overseas[1-4].

\section{Comparison between Family Care and Institution Care of the Elderly}

In china, the model of family care of the elderly has long history and rich experience. [5] Family care of the elderly consists of care in life and affective interaction. First, the younger generation can support the elderly for cloth, feed and traffic etc. in life. Second, the elderly can get spiritual and emotional comfort from the younger generation. In family life, getting psychic dependence from and emotional communication with the younger generation, the elderly can acquire the belonging sense and mental comfort.
However the implement of birth control policy has strong impact on the traditional concept that raising sons can afford the elderly. As the birth control of the basic country policy is put into practice, a couple is allowed to give birth to only one child, as a result, the family constitutes of three persons- one child and two parents. And then traditional family changes into ' 421 ' family structure that constitutes of a couple, a child and four parents. Meanwhile, this model of family is increasing rapidly. In modern society, facing with cruel social competition, a younger couple has unparalleled burden for supporting one child and four parents from two different family. In addition, over two thirds married adults live apart from their parents, so many empty-nest elderly who have companions emerge out in country and city. Due to transformation of family structure, the traditional way of supporting the elderly is not fitted for current situation.

As aged tendency of population aggravates and family structural model transforms, how to solve the problem of caring the elderly has become an important thing to many family. However, in order to realize the elderly cared and supported, it is not enough only staying in the model of homebase care for the aged. The advantages of institution care of the elderly lie in keeping safety, because most institution of care the elderly have caregivers with rich experience who can provide for one to three different grade nurse services, or special nurse service for some special the elderly. The caregivers come any time when the elderly need service. While some institution has better condition, with doctors 24 hours full time. Compared with safety of the elderly living alone, the safety of old people' institution is better.

However, with regard to institution care of the elderly, there are many problems needed to be solved. Old people' institution with simple and rude condition only can provide for basic service such as feed and live, shortage of concern and love, and cannot protect privacy of the elderly. At present, most old people' institution has many conditions to receive the elderly. The institution claim that the elderly is healthy, free from infection, mental disease and senile dementia, and can fit for collective living. Due to shortage of nurse resource, the elderly who can basically live on his own is easy to find an old people' institution. But the elderly who need special service and medical care is difficult to find a suited institution. At the end of 2011 year, nursing homes beds are 3.15 million in all kinds of institution care of the elderly in China, constituting $1.77 \%$ of total the elderly population. According to the data of Beijing civil affairs bureau, the number of total institution care 
of the elderly is 401, and the number of public institutions is 215 , with private institution 186 . The elderly own only 2.9 nursing homes beds per hundred. Beijing first social welfare institute has 1100 nursing homes beds, however there are over seven thousands people waiting to live in, so if one elderly want to live in institution, he must wait for ten years. Due to high cost, institution care of the elderly is only fit for middle class family, not fit for common family. Public institution is different to entre in, with some private institution expensive and others cheap but short of mental care.

Comparison of all kinds of institutions care of the elderly in Beijing

\begin{tabular}{|c|c|c|c|}
\hline & Public old people' institution & $\begin{array}{l}\text { Private old people' institution at high } \\
\text { price }\end{array}$ & $\begin{array}{l}\text { Private old people' institution at } \\
\text { low price }\end{array}$ \\
\hline Accommodation condition & $\begin{array}{l}\text { Many people wait for entering in } \\
\text { old people 'institution; } \\
\text { Don't receive for the people that } \\
\text { cannot take care themselves; } \\
\text { Need for interview. }\end{array}$ & A lot of quota of people & $\begin{array}{l}\text { Unoccupied nursing homes } \\
\text { beds }\end{array}$ \\
\hline Price & 1500-2000 RMB per month & $10000 \mathrm{RMB}$ or high per month & 2000-2700 RMB per month \\
\hline Environmental facility & $\begin{array}{l}\text { Many stages for organizing interest } \\
\text { group }\end{array}$ & $\begin{array}{l}\text { Prefect equipment (restaurant, supermart, } \\
\text { snooker room, hydrotherapy, pedicure } \\
\text { and painting and calligraphy room) star } \\
\text { hotel standard. }\end{array}$ & $\begin{array}{l}\text { Small room, bad environment } \\
\text { and lack stages for the elderly }\end{array}$ \\
\hline Medical resource allocation & $\begin{array}{l}\text { Short of suited metal doctor for } \\
\text { care the elderly in street institution }\end{array}$ & Professional treatment room and doctor & $\begin{array}{l}\text { Lack professional treatment } \\
\text { room and doctor, and nursing } \\
\text { workers with bad skills. }\end{array}$ \\
\hline Location & Street of city & Urban area & suburbs \\
\hline Popularity & First choice & Second choice & Last choice \\
\hline
\end{tabular}

\section{Model of Community Service for Home Care of the Elderly}

Community service for home care of the elderly is that the elderly still live their family and community environment, with 'community support' or 'community care'. Community care is a way that the elderly are supported for different services through government and society, and then assisted to lengthen living in family. This way can make the elderly possess ability to take care of themselves, and improve their life quality. Once becoming older, a person will be easy to have mentality of staying in home. The elderly are easy to have lost, melancholy and lonely emotion once entering in the unfamiliar surroundings. Taking advantages of community service resources, the elderly are supported in familiar family and community environment. It is a best and suited way of model of care the elderly. But the precondition of implementing this model of care the elderly is that all kinds of adequate and systematic service develop maturely and perfectly. Community service for home care of the elderly that has socialization professional and non-professional service, with the help of community residents committee has become innovation research in new type model of social provision for the elderly.

First, establish mutual-help group of the aged, organize community to launch mutual assistance activity. Some consecratory the elderly take part in the activity voluntarily, giving play to their specialty in caring the elderly. They also provide for homemaking, entertainment, sports and medical treatment.
Second, establish and improve the service network of whole community elderly welfare. According to 'Starlight plan' implemented by Ministry of Civil Affairs, boosting the construction of community welfare, service system of caring the elderly in community have gradually become socialization and industrialization. For example, there are community health care station, nursing home, care center and cultural activity centre and so on. And then the service network of the elderly community is constructed with community construction. Doorto-door service can be provided for the elderly with inconvenient action, and volunteers can be organized to care and serve daily for the elderly.

Third, establish 'charity and love ring' and door-to-door service. Call terminals are stalled in house for the elderly living alone. The elderly can use the call terminal to call care center to help, when in critical situation and need of help. Meanwhile, volunteer team can be organized to provide doorto-door service for alone, ill, disabled and weak group throughout the year, to solve the anxious, difficult and worried problem. The volunteer will come to service, when the elderly press 'love ring'.

In addition, empty-nest and alone elderly face with the problem of shortage of the spirit care. Compared with ache corporeally, shortage of spiritual consolation brings much hurt to empty-nest and alone elderly. Empty-nest elderly can not enjoy big family happiness. Meanwhile, their ability of communication with neighborhood becomes weak, so the elderly is easy to generate aloneness. The elderly who usually stay alone and rarely communicate with others is easy to generate pessimistic mood, even may suffer from depressive 
symptom and generate suicide idea. The old people's mental health and spiritual consolation need to be given much attention. According to insufficient listed above, a new-type social provision for the aged idea is tried to be proposed.

The first model : The elderly who lose their mate can form a new family and live together. Community residents committee act matchmaker to bring the elderly having lost their mate together. The elderly can find a new elderly mate and begin their new family life. The new family life can bring warm to the elderly and make the elderly not alone at emotion.

The second model: a new family constitutes of the alone elderly and child. With regard to the elderly who build a new family according to the first model, if the elderly long for child and enjoy family happiness, the neighborhood committee can assist them to adopt an orphan with stand-alone capability and build a family of three people. With regard to the elderly who don't want to look for partner but hope to raise a child, the neighborhood committee also can assist him to adopt a child with stand-alone capability.

The third model: the simulated family constitutes of kindergarten children whose parents are too busy to take care of them at daytime. The empty-nest elderly eagerly long for family happiness because their children are not around. So they long for family happiness. With regard to office workers, their parents are not at their side, so they have no time and vigor to take care for their children at daytime. And then empty-nest elderly in community and office worker can build a simulated family. The simulated family can make the elderly enjoy family happiness, get emotional comfort. Meanwhile, it can also solve the problem that office workers cannot care their children.

\section{Conclusions}

Social pension insurance system is built preliminarily in China, but it need to be improved and perfected. Although academic community has launched many forums to discuss problem, the research in diversification and characteristic service are not enough. The model of service for the aged is discussed at new period to find a suited way to solve the problem of insufficient model of care the elderly. Community service for home care of elderly as a new model of care of elderly shows its advantages, but still stay in initial stage, so much joint effort from whole society are needed.

\section{References}

[1] E. S. Andreas, U. A.. Harriet and S. Andrea, A trial of annual in-home comprehensive geriatric assessments for elderly people living in the community, The New England Journal of Medicine, vol.27, pp. 421451, 1992.

[2] E. S. Andreas, E. Matthias and H. Andreas, Home Visits to Prevent Nursing Home Admission and Functional Decline in Elderly People, The Journal of the American Medical Association, vol.287, pp. 10221028, 2002.

[3] G. L. Suzanne, H.W. Edward and D. Connie, Preventing disability and managing chronic illness in frail older adults: a randomized trial of a community-based partnership with primary care, Journal of the American Geriatrics Society, vol.46 no.10.

[4] E. S. Andreas, M. W. Jutta and N. Thorsten, Risk factors for functional status decline in community-living elderly people: a systematic literature review, Social Science \& Medicine, vol.48, pp. 445-469, 1999.

[5] Iris Chi D.S.W, Nelson Chow..Housing and family care for the elderly in Hong Kong. Ageing International, vol.23, pp.65-77, 1997. 